\title{
Photoluminescence and Scintillation Properties of Ce-, Pr-, and Tb-doped $(\mathrm{Gd}, \mathrm{Lu})_{2} \mathrm{Hf}_{2} \mathrm{O}_{7}$ Crystals
}

\author{
Daisuke Nakauchi, Hiroyuki Fukushima, Takumi Kato, \\ Noriaki Kawaguchi, and Takayuki Yanagida \\ Division of Materials Science, Nara Institute of Science and Technology (NAIST), \\ 8916-5 Takayama, Ikoma, Nara 630-0192, Japan
}

(Received October 15, 2021; accepted November 5, 2021)

Keywords: scintillator, photoluminescence, radioluminescence, phosphor, dosimetry

$\mathrm{Gd}_{2} \mathrm{Hf}_{2} \mathrm{O}_{7}$ and $\mathrm{Lu}_{2} \mathrm{Hf}_{2} \mathrm{O}_{7}$ single crystals doped with various rare-earth ions $\left(\mathrm{Ce}^{3+}, \mathrm{Pr}^{3+}\right.$, and $\mathrm{Tb}^{3+}$ ) were prepared by the floating zone method to investigate their photoluminescence and scintillation properties. The Ce-doped samples show scintillation signals with a broad peak in the range of 400-600 $\mathrm{nm}$, whereas the $\mathrm{Tb}$ - and Pr-doped samples show relatively strong emission characterized by a few sharp peaks in the range of $480-700 \mathrm{~nm}$ due to $4 \mathrm{f}-4 \mathrm{f}$ transitions of the dopant ions. The scintillation spectra of the Ce-doped $\mathrm{Lu}_{2} \mathrm{Hf}_{2} \mathrm{O}_{7}$ after annealing at various temperatures show significant changes in their shapes, suggesting changes in the valence of the Ce ions.

\section{Introduction}

A scintillator is a phosphor that immediately converts incident ionizing radiation with high energy into UV-visible photons; thus, scintillators have been applied to radiation detection in, for example, medical imaging, ${ }^{(1)}$ security, ${ }^{(2)}$ and geophysical resource exploration. ${ }^{(3)}$ In general, an $\mathrm{X}$ - or $\gamma$-ray scintillator requires a high scintillation light yield $(L Y)$, short decay time, high energy resolution, high density, large effective atomic number, and low afterglow. Therefore, there has been continuous R\&D to develop more desirable materials in single crystal, ${ }^{(4-12)}$ ceramic, ${ }^{(13-15)}$ glass, ${ }^{(16-19)}$ and liquid forms. ${ }^{(20-22)}$

A high density and a large effective atomic number are important for obtaining large cross sections against $\mathrm{X}$ - and $\gamma$-rays; ${ }^{(23)}$ thus, pyrochlore rare-earth hafnates $\left(R E_{2} \mathrm{Hf}_{2} \mathrm{O}_{7}, R E\right.$ : rare earth) are potential scintillators with high density (9.0 and $9.7 \mathrm{~g} / \mathrm{cm}^{3}$ for $\mathrm{Gd}_{2} \mathrm{Hf}_{2} \mathrm{O}_{7}$ and $\mathrm{Lu}_{2} \mathrm{Hf}_{2} \mathrm{O}_{7}$, respectively $\left.{ }^{(24)}\right)$ and large effective atomic numbers (66-69). ${ }^{(25)}$ To date, there have been a few reports on pyrochlore $R E_{2} \mathrm{Hf}_{2} \mathrm{O}_{7}$ but only in a polycrystalline form. ${ }^{(26-31)}$ However, a single-crystal form is preferable for $\mathrm{X}$ - or $\gamma$-ray measurements owing to their high optical transparency, density, and homogeneity. Since the crystal growth of $R E_{2} \mathrm{Hf}_{2} \mathrm{O}_{7}$ is difficult owing to the high melting points $\left(\sim 2400^{\circ} \mathrm{C}\right)$, there have only been a few reports on the crystal growth of pyrochlore $R E_{2} \mathrm{Hf}_{2} \mathrm{O}_{7}$ (e.g., $\mathrm{Nd}_{2} \mathrm{Hf}_{2} \mathrm{O}_{7}{ }^{(32)}$ and $\mathrm{Pr}_{2} \mathrm{Hf}_{2} \mathrm{O}_{7}{ }^{(33)}$ ). In our previous works, $\mathrm{La}_{2} \mathrm{Hf}_{2} \mathrm{O}_{7}$,

*Corresponding author: e-mail: nakauchi@ms.naist.jp

https://doi.org/10.18494/SAM3696

Modified: February 24, 2022 
$\mathrm{Gd}_{2} \mathrm{Hf}_{2} \mathrm{O}_{7}$, and $\mathrm{Lu}_{2} \mathrm{Hf}_{2} \mathrm{O}_{7}$ single crystals were successfully synthesized using an optical floating zone furnace equipped with Xe lamps, and the scintillation properties of the single crystals were reported for the first time. ${ }^{(34)}$ The optical floating zone method is a powerful means of searching for oxide scintillators having high melting points. To improve the scintillation properties, $\mathrm{Zr}$ and Ti ions have been doped into $R E_{2} \mathrm{Hf}_{2} \mathrm{O}_{7}$ crystals to distort the crystal lattice because Hf-based oxide materials typically show luminescence due to oxygen vacancies. ${ }^{(35,36)}$ Significant enhancements of the scintillation $L Y$ by such substitution were also observed in $\mathrm{La}_{2} \mathrm{Hf}_{2} \mathrm{O}_{7}$ and $\mathrm{Gd}_{2} \mathrm{Hf}_{2} \mathrm{O}_{7}{ }^{(37,38)}$ however, the scintillation properties were still unsatisfactory, and different approaches are required. In this study, to clarify the behavior of doped luminescence centers in pyrochlore $R E_{2} \mathrm{Hf}_{2} \mathrm{O}_{7}$, we investigated the use of trivalent rare-earth ions $\left(\mathrm{Ce}^{3+}, \mathrm{Pr}^{3+}\right.$, and $\left.\mathrm{Tb}^{3+}\right)$ as activators, which show efficient luminescence in the UV-visible region in many scintillator hosts.

\section{Materials and Methods}

The tested compositions were (Ce, $\mathrm{Pr}, \mathrm{Tb})_{0.02}(\mathrm{Gd}, \mathrm{Lu})_{1.98} \mathrm{Hf}_{2} \mathrm{O}_{7} . \mathrm{CeO}_{2}(99.99 \%), \operatorname{Pr}_{6} \mathrm{O}_{11}$ (99.99\%), $\mathrm{Tb}_{4} \mathrm{O}_{7}(99.99 \%), \mathrm{Gd}_{2} \mathrm{O}_{3}(99.99 \%), \mathrm{Lu}_{2} \mathrm{O}_{3}(99.999 \%)$, and $\mathrm{HfO}_{2}(99.95 \%)$ were used as raw powders. First, a homogeneously mixed powder was formed into cylinder rods by hydrostatic pressure, then the rods were sintered at $1400{ }^{\circ} \mathrm{C}$ for $8 \mathrm{~h}$ in air. After that, crystals were grown by the optical floating zone method (FZ-T-12000-X-VPO-PC-YH, Crystal Systems). ${ }^{(34)}$ Here, the pulling-down rate and the rotation rate were $30 \mathrm{~mm} / \mathrm{h}$ and $3 \mathrm{rpm}$, respectively. To clarify the crystalline phase, powder X-ray diffraction (XRD) patterns were measured using a diffractometer (MiniFlex600, Rigaku) over the $2 \theta$ range from 3 to $90^{\circ}$. Photoluminescence (PL) $3 \mathrm{D}$ spectra and quantum yields $(Q Y \mathrm{~s})$ were measured using a Quantaurus-QY spectrometer (C11347, Hamamatsu Photonics), and decay times were evaluated using a Quantaurusspectrometer (C11367, Hamamatsu Photonics).

As scintillation properties, scintillation spectra under X-ray irradiation were measured using our original setup. ${ }^{(39)}$ The X-ray generator (XRB80N100/CB, Spellman) was equipped with an $\mathrm{X}$-ray tube having a $\mathrm{W}$ anode target and a Be window. The X-ray tube was operated with a bias voltage of $80 \mathrm{kV}$ and tube current of $1.2 \mathrm{~mA}$. In these analyses, the scintillation photons emitted from the samples were led to a spectrometer unit equipped with a CCD (DU-420-BU2, Andor) and a monochromator (SR163, Andor) through an optical fiber. Here, the detector was cooled to $188 \mathrm{~K}$ by a Peltier module to reduce the thermal noise.

\section{Results and Discussion}

The sizes of the as-prepared $\mathrm{Gd}_{2} \mathrm{Hf}_{2} \mathrm{O}_{7}$ and $\mathrm{Lu}_{2} \mathrm{Hf}_{2} \mathrm{O}_{7}$ crystals were 4-6 $\mathrm{mm} \phi \times 10-20 \mathrm{~mm}$ length, and the samples were cut and polished for characterization. Figure 1 shows photographs of the polished $\mathrm{Gd}_{2} \mathrm{Hf}_{2} \mathrm{O}_{7}$ and $\mathrm{Lu}_{2} \mathrm{Hf}_{2} \mathrm{O}_{7}$ samples. The Ce-doped samples were colorless, while the Pr- and Tb-doped samples were brown and transparent under room light. As shown in Fig. 1 (bottom), when exposed to UV light (254 nm), the Pr-doped samples show red emission and the Tb-doped samples exhibit yellow emission, which can be seen by the naked eye. Figure 2 shows 


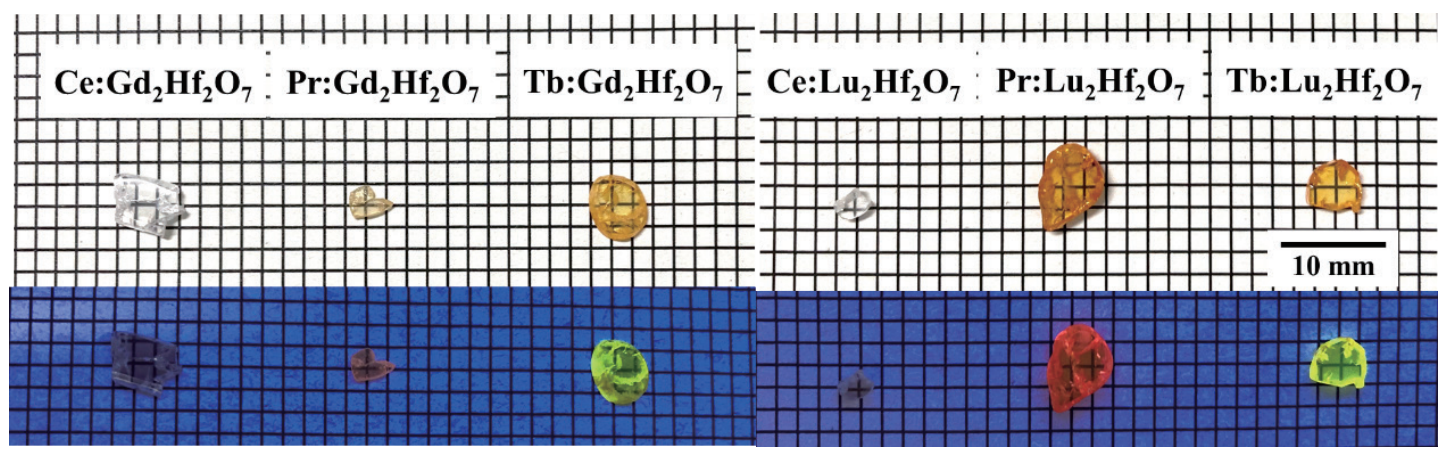

Fig. 1. (Color online) Photographs of synthesized $\mathrm{Gd}_{2} \mathrm{Hf}_{2} \mathrm{O}_{7}$ and $\mathrm{Lu}_{2} \mathrm{Hf}_{2} \mathrm{O}_{7}$ single crystals under room light (top) and UV lamp (254 nm) (bottom).

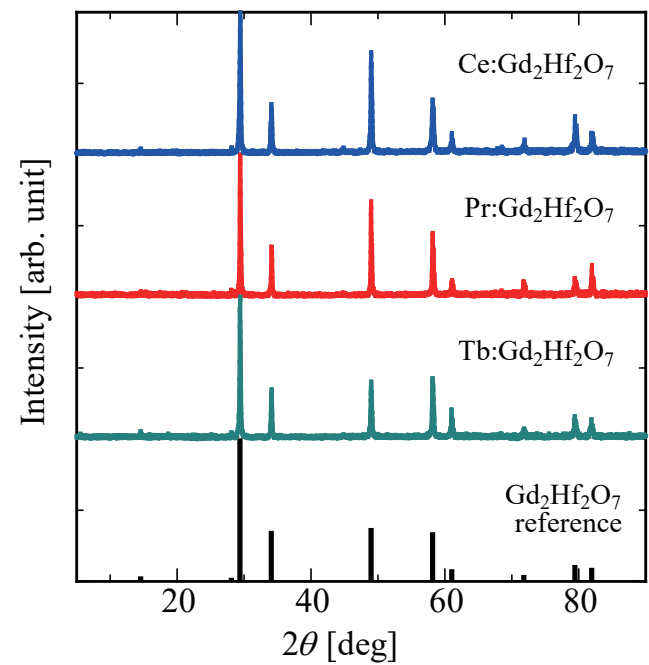

(a)

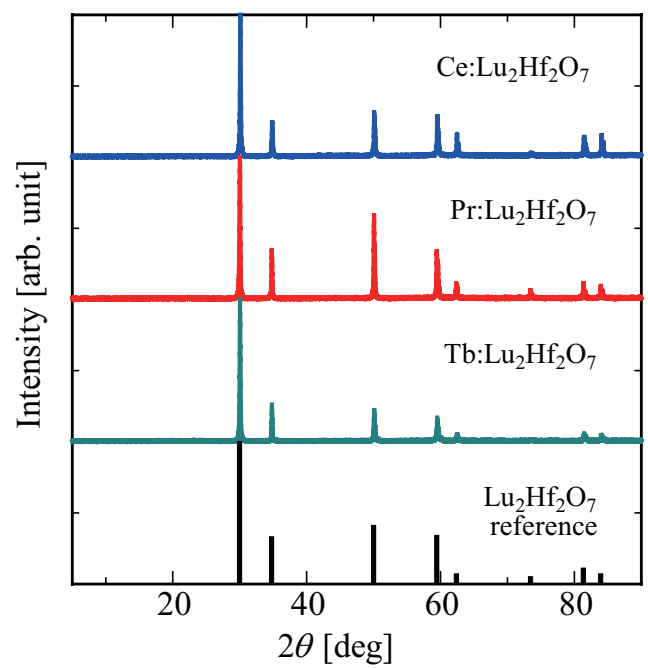

(b)

Fig. 2. (Color online) Powder XRD patterns of synthesized (a) $\mathrm{Gd}_{2} \mathrm{Hf}_{2} \mathrm{O}_{7}$ and (b) $\mathrm{Lu}_{2} \mathrm{Hf}_{2} \mathrm{O}_{7}$.

the XRD patterns of the $\mathrm{Gd}_{2} \mathrm{Hf}_{2} \mathrm{O}_{7}$ and $\mathrm{Lu}_{2} \mathrm{Hf}_{2} \mathrm{O}_{7}$ crystalline powders. On the basis of comparison with the reference pattern, ${ }^{(40)}$ the XRD patterns demonstrate that the samples have only one phase of pyrochlore with cubic symmetry and a space group of Fd $\mathrm{m}$, and no impurity phase is observed. No peak shift due to the use of a different dopant can be observed, which is probably due to the similar ionic radii of the dopants to those of the sites in the host lattice (1.14 $\AA$ for $\mathrm{Ce}^{3+}, 1.05 \AA$ for $\mathrm{Gd}^{3+}$, and $0.98 \AA$ for $\mathrm{Lu}^{3+}$ in eight-coordination).

Figure 3 shows the PL 3D spectra of the samples, where the vertical and horizontal axes show excitation and emission wavelengths, respectively. The Ce-doped samples do not show any emission signal in these measurements. The Pr-doped samples exhibit emission signals with several sharp peaks due to $4 \mathrm{f}-4 \mathrm{f}$ transitions $\left({ }^{1} \mathrm{D}_{2} \rightarrow{ }^{3} \mathrm{H}_{4},{ }^{3} \mathrm{P}_{0} \rightarrow{ }^{3} \mathrm{H}_{6},{ }^{3} \mathrm{P}_{0} \rightarrow{ }^{3} \mathrm{~F}_{2}\right.$, and $\left.{ }^{3} \mathrm{P}_{0} \rightarrow{ }^{3} \mathrm{~F}_{3}\right)$ in the range of 600-660 nm, and the $Q Y \mathrm{~s}$ are $4.0 \%$ for $\operatorname{Pr}: \mathrm{Gd}_{2} \mathrm{Hf}_{2} \mathrm{O}_{7}$ and $5.1 \%$ for $\operatorname{Pr}: \mathrm{Lu}_{2} \mathrm{Hf}_{2} \mathrm{O}_{7}$ under excitation at $280 \mathrm{~nm}$. However, no emission peaks at $400-550 \mathrm{~nm}$ can be observed, as reported for other materials. ${ }^{(41)}$ The bandgap energy of $R E_{2} \mathrm{Hf}_{2} \mathrm{O}_{7}$ was reported to be $3-4 \mathrm{eV}{ }^{(42)}$ and the 

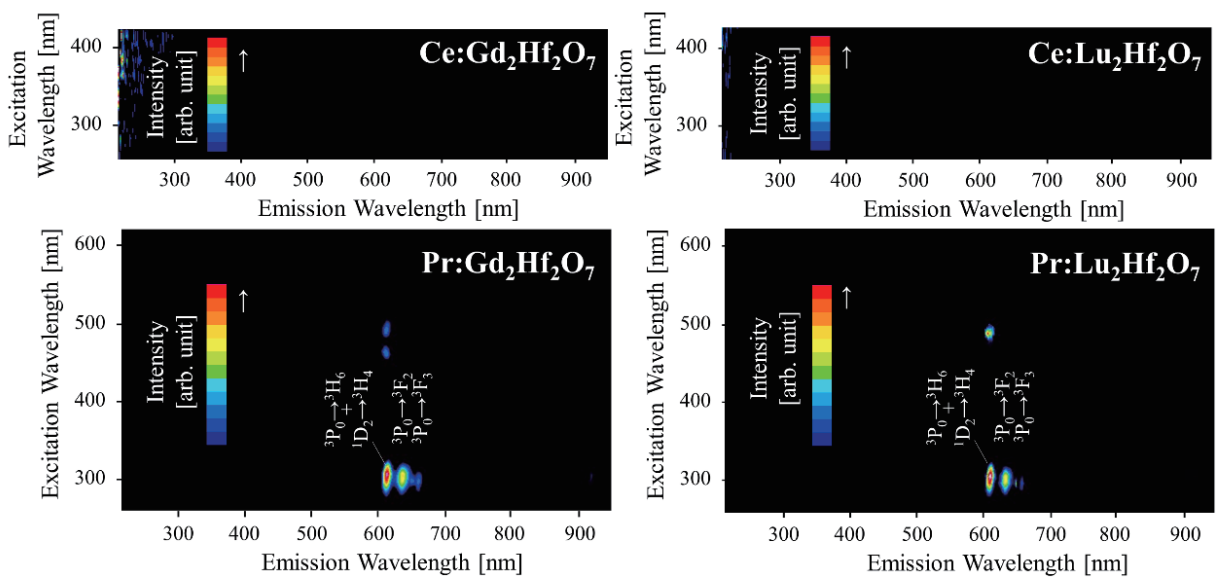

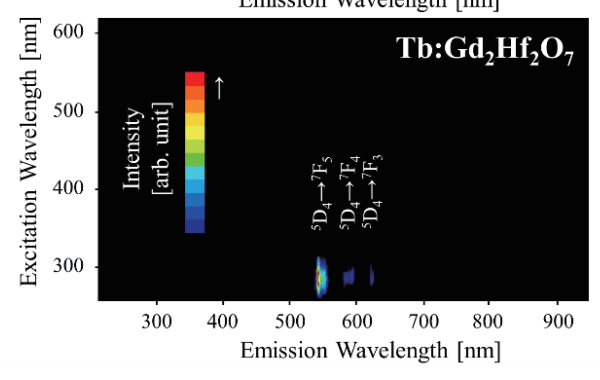

(a)

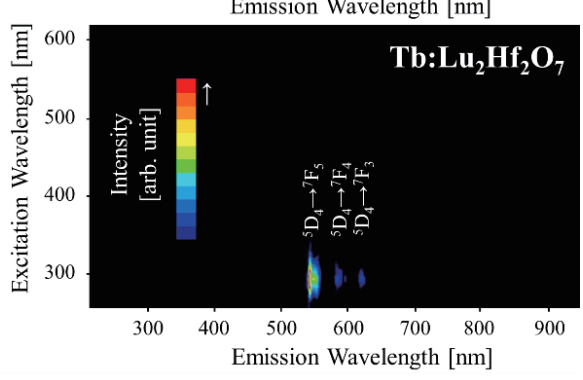

(b)

Fig. 3. (Color online) PL 3D spectra of (a) $\mathrm{Gd}_{2} \mathrm{Hf}_{2} \mathrm{O}_{7}$ and (b) $\mathrm{Lu}_{2} \mathrm{Hf}_{2} \mathrm{O}_{7}$ single crystals.

conduction band does not decrease the luminescence at $450-600 \mathrm{~nm}$. According to past studies, ${ }^{(43,44)}$ the absorption band at $400-600 \mathrm{~nm}$ due to the $\mathrm{O}^{2-}-\mathrm{Pr}^{4+}$ charge transfer process resulted in the red coloring of the samples. The $\mathrm{Hf}^{4+}$ site at the $R E_{2} \mathrm{Hf}_{2} \mathrm{O}_{7}$ host might change some of the doped $\mathrm{Pr}$ ions to $\mathrm{Pr}^{4+}$, and the absorption should decrease the emission peaks at 450-600 nm. The Tb-doped samples show emission peaks at 550, 590, and $620 \mathrm{~nm}\left({ }^{5} \mathrm{D}_{4} \rightarrow{ }^{7} \mathrm{~F}_{5}\right.$, ${ }^{5} \mathrm{D}_{4} \rightarrow{ }^{7} \mathrm{~F}_{4}$, and ${ }^{5} \mathrm{D}_{4} \rightarrow{ }^{7} \mathrm{~F}_{3}$ ), and the $Q Y$ s are $3.4 \%$ for $\mathrm{Tb}: \mathrm{Gd}_{2} \mathrm{Hf}_{2} \mathrm{O}_{7}$ and $8.1 \%$ for $\mathrm{Tb}: \mathrm{Lu}_{2} \mathrm{Hf}_{2} \mathrm{O}_{7}$ under excitation at $280 \mathrm{~nm}$. To demonstrate the origin of the emission, the PL decay time was evaluated as shown in Figs. 4 and 5. The decay curves monitored at $610 \mathrm{~nm}$ under excitation at 420-460 nm were measured for the Pr-doped samples. The decay curves can be approximated from the sum of two exponential decay functions with decay time constants of $\sim 30\left(\tau_{1}\right)$ and $\sim 200 \mu \mathrm{s}\left(\tau_{2}\right)$. These values are reasonable for the $4 \mathrm{f}-4 \mathrm{f}$ transitions of $\mathrm{Pr}^{3+}$ reported for other materials ${ }^{(45,46)}$ and are attributable to relaxation from ${ }^{3} \mathrm{P}_{0}$ and ${ }^{2} \mathrm{D}_{1}$ excited states. The decay curves of the Tb-doped samples monitored at $550 \mathrm{~nm}$ under excitation at 300-380 nm are well fitted by one exponential decay component with a decay time constant of 150-200 $\mu$ s, which is almost the same as that for the typical decay of $\mathrm{Tb}^{3+}$ reported in past studies. ${ }^{(12)}$

Figures 6 and 7 show the X-ray-induced scintillation spectra of the $\mathrm{Gd}_{2} \mathrm{Hf}_{2} \mathrm{O}_{7}$ and $\mathrm{Lu}_{2} \mathrm{Hf}_{2} \mathrm{O}_{7}$ samples, respectively. Unlike in the PL spectra, the Ce-doped samples exhibit a broad emission band in the range of 400-600 $\mathrm{nm}$. Since the emission features are similar to those of undoped ones reported elsewhere, ${ }^{(34)}$ the origin of the broad emission is intrinsic luminescence. For the Pr- and Tb-doped samples, the spectra have similar shapes to the PL spectra. The Pr-doped 


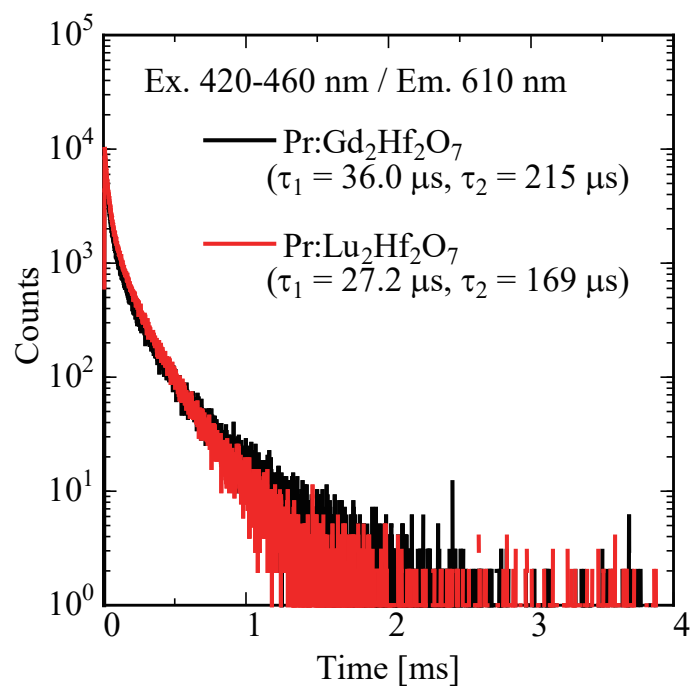

Fig. 4. (Color online) PL decay curves of Pr-doped $\mathrm{Gd}_{2} \mathrm{Hf}_{2} \mathrm{O}_{7}$ and $\mathrm{Lu}_{2} \mathrm{Hf}_{2} \mathrm{O}_{7}$ single crystals.

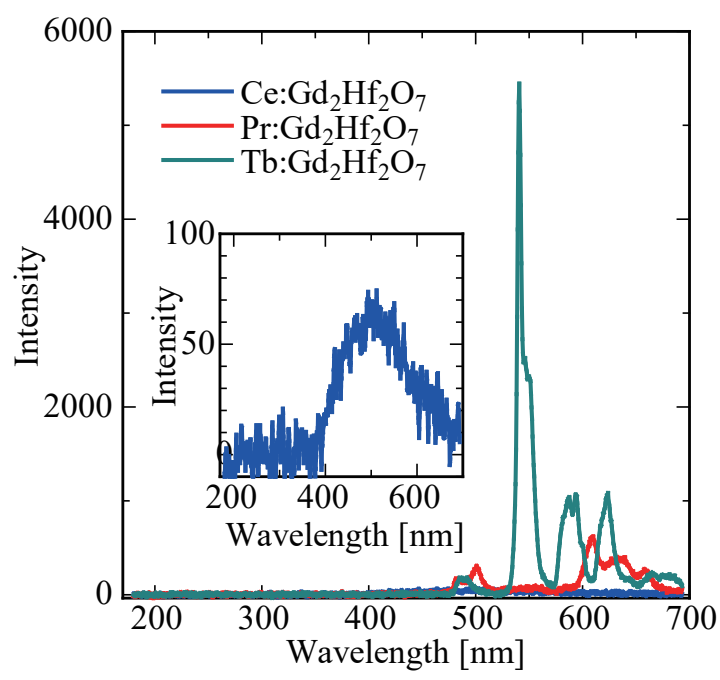

Fig. 6. (Color online) X-ray-induced scintillation spectra of $\mathrm{Gd}_{2} \mathrm{Hf}_{2} \mathrm{O}_{2}$ single crystals. The inset shows the enlarged spectrum of the Ce-doped material.

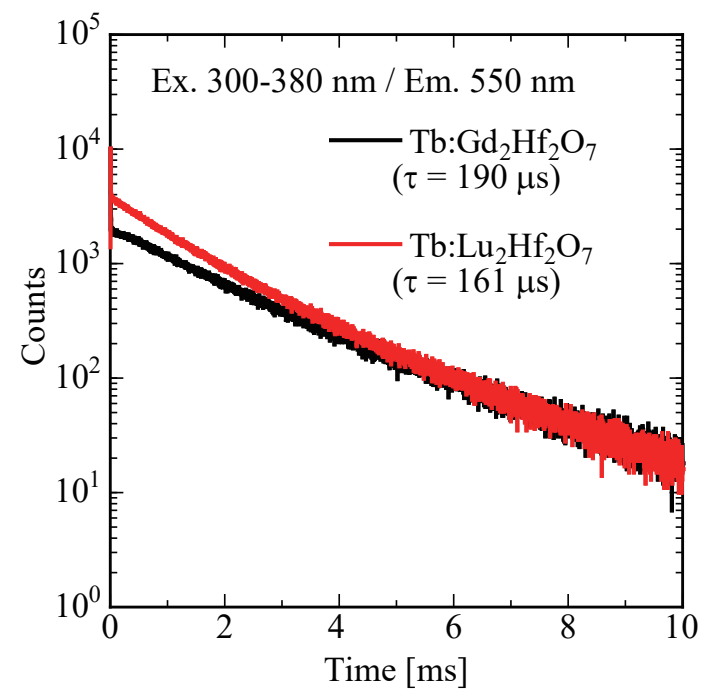

Fig. 5. (Color online) PL decay curves of Tb-doped $\mathrm{Gd}_{2} \mathrm{Hf}_{2} \mathrm{O}_{7}$ and $\mathrm{Lu}_{2} \mathrm{Hf}_{2} \mathrm{O}_{7}$ single crystals.

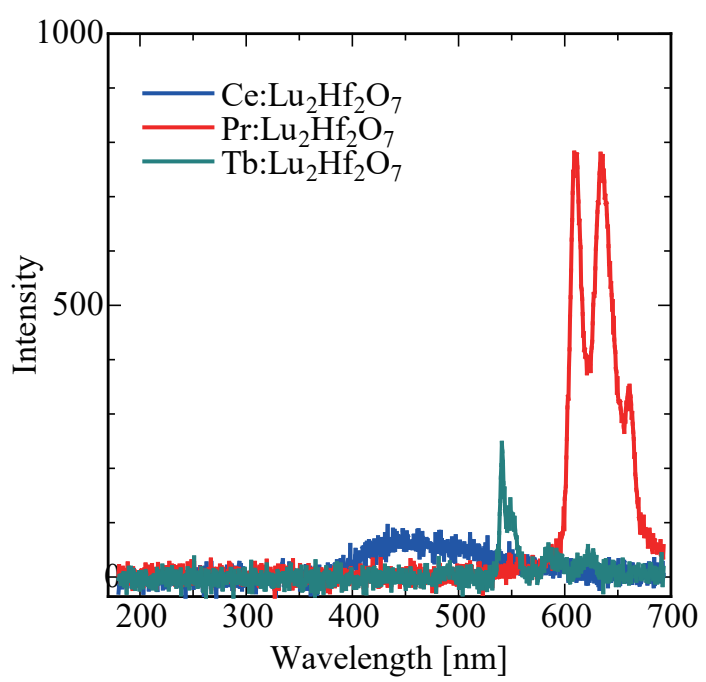

Fig. 7. (Color online) X-ray-induced scintillation spectra of $\mathrm{Lu}_{2} \mathrm{Hf}_{2} \mathrm{O}_{7}$ single crystals.

samples show scintillation with several sharp peaks at $500\left({ }^{3} \mathrm{P}_{0} \rightarrow{ }^{3} \mathrm{H}_{4}\right), 610\left({ }^{1} \mathrm{D}_{2} \rightarrow{ }^{3} \mathrm{H}_{4}\right.$ and $\left.{ }^{3} \mathrm{P}_{0} \rightarrow{ }^{3} \mathrm{H}_{6}\right), 630\left({ }^{3} \mathrm{P}_{0} \rightarrow{ }^{3} \mathrm{~F}_{2}\right)$, and $660 \mathrm{~nm}\left({ }^{3} \mathrm{P}_{0} \rightarrow{ }^{3} \mathrm{~F}_{3}\right)$ due to $\mathrm{Pr}^{3+}$. The Tb-doped samples show a few emission peaks at $550\left({ }^{5} \mathrm{D}_{4} \rightarrow{ }^{7} \mathrm{~F}_{5}\right), 590\left({ }^{5} \mathrm{D}_{4} \rightarrow{ }^{7} \mathrm{~F}_{4}\right)$, and $620 \mathrm{~nm}\left({ }^{5} \mathrm{D}_{4} \rightarrow{ }^{7} \mathrm{~F}_{3}\right)$ due to $\mathrm{Tb}^{3+}$. Although the scintillation characterizations are qualitative, the $\mathrm{Tb}: \mathrm{Gd}_{2} \mathrm{Hf}_{2} \mathrm{O}_{7}$ sample seems to show the highest emission intensity among the present samples.

Figure 8 shows the scintillation spectra of the Ce-doped $\mathrm{Lu}_{2} \mathrm{Hf}_{2} \mathrm{O}_{7}$ after annealing with carbon powder under vacuum at various temperatures $\left(1200,1400,1600\right.$, and $1800^{\circ} \mathrm{C}$ for $2 \mathrm{~h}$ ) to clarify the causes of luminescence quenching in the present samples. Significant changes in the 


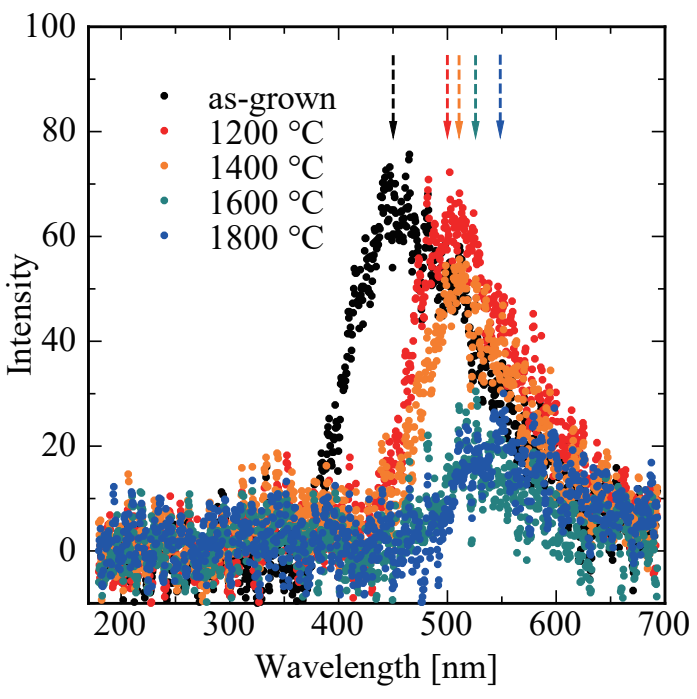

Fig. 8. (Color online) X-ray-induced scintillation spectra of $\mathrm{Ce}: \mathrm{Lu}_{2} \mathrm{Hf}_{2} \mathrm{O}_{7}$ single crystals after annealing under a reductive condition at various temperatures for $2 \mathrm{~h}$. The arrows show the peak positions of the emission spectra.

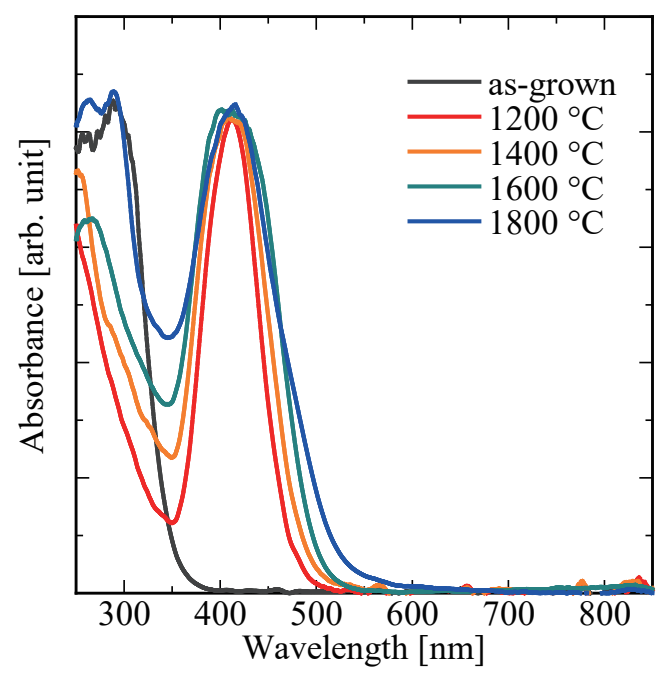

Fig. 9. (Color online) Absorption spectra of $\mathrm{Ce}: \mathrm{Lu}_{2} \mathrm{Hf}_{2} \mathrm{O}_{7}$ single crystals after annealing under a reductive condition at various temperatures for $2 \mathrm{~h}$.

spectral shape with the annealing temperature can be observed. With increasing annealing temperature, the peak position is shifted to a longer wavelength (see dotted arrows in Fig. 8). To clarify the phenomena, the absorption spectra of the samples were measured as shown in Fig. 9. The as-grown samples show only an absorption peak at $300 \mathrm{~nm}$, whereas the annealed samples show an absorption peak at $410 \mathrm{~nm}$. Since the absorption peak becomes broad with increasing annealing temperature, the spectral shape in Fig. 8 appears to be changed by absorption at $400-$ $450 \mathrm{~nm}$ newly generated by annealing. Whereas the ionic radius of $\mathrm{Ce}^{3+}$ is close to those of $\mathrm{Gd}^{3+}$ and $\mathrm{Lu}^{3+}$, the ionic radius of $\mathrm{Ce}^{4+}$ is also relatively close to that of $\mathrm{Hf}^{4+}$. Therefore, it is considered that the $\mathrm{Hf}^{4+}$ sites in the $R E_{2} \mathrm{Hf}_{2} \mathrm{O}_{7}$ host suppressed the reductive reaction from $\mathrm{Ce}^{4+}$ to $\mathrm{Ce}^{3+}$, and the tetravalent ion became dominant. It has been reported that the reductive reaction of $\mathrm{CeO}_{2}$ proceeds through the formation of oxygen vacancies; ${ }^{(47,48)}$ thus, annealing under reductive conditions will promote the generation of oxygen vacancies and the subsequent reduction of $\mathrm{Ce}^{4+}$ to trivalent states. The results suggest that $\mathrm{Pr}$ and $\mathrm{Tb}$ also partly remain as tetravalent ions, which may degrade the luminescence characteristics.

\section{Conclusions}

Ce-, Pr-, and Tb-doped $\mathrm{Gd}_{2} \mathrm{Hf}_{2} \mathrm{O}_{7}$ and $\mathrm{Lu}_{2} \mathrm{Hf}_{2} \mathrm{O}_{7}$ single crystals were successfully grown by the floating zone method, and their PL and scintillation properties were investigated. The Cedoped samples show no significant emission signal due to $\mathrm{Ce}^{3+}$, and only intrinsic luminescence can be observed under X-ray irradiation. On the other hand, both the Tb- and Pr-doped samples show PL and scintillation with a few sharp peaks due to $4 \mathrm{f}-4 \mathrm{f}$ transitions of trivalent ions. The 
scintillation spectra of the Ce-doped $\mathrm{Lu}_{2} \mathrm{Hf}_{2} \mathrm{O}_{7}$ after annealing under reductive conditions show significant changes in their shapes, suggesting changes in the valence of $\mathrm{Ce}$ ions. From the results, the $\mathrm{Hf}^{4+}$ site in host compounds is considered to interfere with the preferential substitution of ions and lead to inefficient luminescence properties.

\section{Acknowledgments}

This work was supported by Grants-in-Aid for Scientific Research B (19H03533, 21H03733, and 21H03736) and Early-Career Scientists (20K20104) from the Japanese Society of Applied Physics (JSPS). Grants from Japan Science and Technology Agency (JST) A-STEP (JPMJTM20FP), Cooperative Research Project of Research Center for Biomedical Engineering, Nippon Sheet Glass Foundation, SEI Group CSR Foundation, TEPCO Memorial Foundation, KRF Foundation, and Murata Science Foundation are also acknowledged.

\section{References}

1 L. Pidol, A. Khan-Harari, B. Viana, B. Ferrand, P. Dorenbos, J. T. M. de Haas, C. W. E. van Eijk, and E. Virey: J. Phys. Condens. Matter 15 (2003) 2091.

2 J. Glodo, Y. Wang, R. Shawgo, C. Brecher, R. H. Hawrami, J. Tower, and K. S. Shah: Phys. Procedia 90 (2017) 285.

3 C. L. Melcher: Nucl. Instrum. Methods Phys. Res., Sect. B 40-41 (1989) 1214.

4 T. Yanagida, Y. Fujimoto, M. Arai, M. Koshimizu, T. Kato, D. Nakauchi, and N. Kawaguchi: Sens. Mater. 32 (2020) 1351.

5 P. Kantuptim, M. Akatsuka, D. Nakauchi, T. Kato, N. Kawaguchi, and T. Yanagida: Sens. Mater. 32 (2020) 1357.

6 M. Akatsuka, D. Nakauchi, T. Kato, N. Kawaguchi, and T. Yanagida: Sens. Mater. 32 (2020) 1373.

7 A. Horimoto, N. Kawano, D. Nakauchi, H. Kimura, M. Akatsuka, and T. Yanagida: Sens. Mater. 32 (2020) 1395.

8 Y. Fujimoto, D. Nakauchi, T. Yanagida, M. Koshimizu, H. Fukada, Y. Hayashi, and K. Asai: Sens. Mater. 32 (2020) 1453.

9 M. Koshimizu, N. Kawano, A. Kimura, S. Kurashima, M. Taguchi, Y. Fujimoto, and K. Asai: Sens. Mater. 33 (2021) 2137.

10 Y. Fujimoto, D. Nakauchi, T. Yanagida, M. Koshimizu, and K. Asai: Sens. Mater. 33 (2021) 2147.

11 P. Kantuptim, H. Fukushima, H. Kimura, D. Nakauchi, T. Kato, M. Koshimizu, N. Kawaguchi, and T. Yanagida: Sens. Mater. 33 (2021) 2195.

12 D. Nakauchi, T. Kato, N. Kawaguchi, and T. Yanagida: Sens. Mater. 33 (2021) 2203.

13 H. Kimura, T. Kato, D. Nakauchi, N. Kawaguchi, and T. Yanagida: Sens. Mater. 32 (2020) 1381.

14 N. Kawaguchi, G. Okada, Y. Futami, D. Nakauchi, T. Kato, and T. Yanagida: Sens. Mater. 32 (2020) 1419.

15 D. Nakauchi, G. Okada, and T. Yanagida: J. Ceram. Soc. Jpn. 124 (2016) 546.

16 A. Ishikawa, A. Yamazaki, K. Watanabe, S. Yoshihashi, A. Uritani, Y. Sakurai, H. Tanaka, R. Ogawara, M. Suda, and T. Hamano: Sens. Mater. 32 (2020) 1489.

17 T. Yanagida, Y. Fujimoto, H. Masai, G. Okada, T. Kato, D. Nakauchi, and N. Kawaguchi: Sens. Mater. 33 (2021) 2179.

18 N. Kawaguchi, H. Masai, M. Akatsuka, D. Nakauchi, T. Kato, and T. Yanagida: Sens. Mater. 33 (2021) 2215.

19 D. Shiratori, D. Nakauchi, T. Kato, N. Kawaguchi, and T. Yanagida: Sens. Mater. 32 (2020) 1365.

20 A. Watanabe, A. Magi, M. Koshimizu, A. Sato, Y. Fujimoto, and K. Asai: Sens. Mater. 33 (2021) 2251.

21 A. Watanabe, A. Magi, A. Yoko, G. Seong, T. Tomai, T. Adschiri, Y. Hayashi, M. Koshimizu, Y. Fujimoto, and K. Asai: Nanomaterials 11 (2021) 1124.

22 S. Arai, T. Noguchi, T. Aida, A. Yoko, T. Tomai, T. Adschiri, M. Koshimizu, Y. Fujimoto, and K. Asai: J. Ceram. Soc. Jpn. 127 (2019) 28.

23 Y. Fujimoto, K. Saeki, D. Nakauchi, T. Yanagida, M. Koshimizu, and K. Asai: Sens. Mater. 30 (2018) 1577.

24 M. J. Weber and R. R. Monchamp: J. Appl. Phys. 44 (1973) 5495. 
L. H. Brixner and E. Station: Mater. Res. Bull. 19 (1984) 143.

Y. Eagleman, M. Weber, and S. Derenzo: J. Lumin. 137 (2013) 93.

Y. Eagleman, M. Weber, A. Chaudhry, and S. Derenzo: J. Lumin. 132 (2012) 2889.

K. Wahid, M. Pokhrel, and Y. Mao: J. Solid State Chem. 245 (2017) 89.

J. Trojan-Piegza, S. Gierlotka, E. Zych, and W. Lojkowski: J. Am. Ceram. Soc. 97 (2014) 1595.

Y. Ji, D. Jiang, and J. Shi: J. Mater. Res. 20 (2005) 567.

1 M. Pokhrel, K. Wahid, and Y. Mao: J. Phys. Chem. C 120 (2016) 14828.

2 J. Chun, P. G. Reuvekamp, D. Chen, C. Lin, and R. K. Kremer: J. Mater. Chem. C 3 (2015) 491.

33 M. C. Hatnean, R. Sibille, M. R. Lees, M. Kenzelmann, V. Ban, V. Pomjakushin, and G. Balakrishnan: J. Phys. Condens. Matter 29 (2017) 075902.

34 D. Nakauchi, G. Okada, N. Kawaguchi, and T. Yanagida: Jpn. J. Appl. Phys. 57 (2018) 100307.

35 N. Umezawa, K. Shiraishi, T. Ohno, M. Boero, H. Watanabe, and T. Chikyow: Physica B 376-377 (2006) 392.

36 K. Tse, D. Liu, K. Xiong, and J. Robertson: Microelectron. Eng. 84 (2007) 2028.

37 D. Nakauchi, N. Kawaguchi, and T. Yanagida: Opt. Mater. 90 (2019) 227.

38 D. Nakauchi, T. Kato, N. Kawaguchi, and T. Yanagida: Sens. Mater. 32 (2020) 1389.

39 T. Yanagida, K. Kamada, Y. Fujimoto, H. Yagi, and T. Yanagitani: Opt. Mater. 35 (2013) 2480.

40 Y. Xu, M. Yamazaki, and P. Villars: Jpn. J. Appl. Phys. 50 (2011) 11RH02.

41 D. Nakauchi, G. Okada, M. Koshimizu, N. Kawaguchi, and T. Yanagida: Phys. B Condens. Matter 530 (2018) 38.

42 N. Li, H. Y. Xiao, X. T. Zu, L. M. Wang, R. C. Ewing, J. Lian, and F. Gao: J. Appl. Phys. 102 (2007) 063704.

43 D. Pawlak, Z. Frukacz, Z. Mierczyk, A. Suchocki, and J. Zachara: J. Alloys Compd. 275-277 (1998) 361.

44 S. Kunimi and S. Fujihara: ECS J. Solid State Sci. Technol. 1 (2012) R32.

45 R. Piramidowicz, R. Mahiou, P. Boutinaud, and M. Malinowski: Appl. Phys. B 104 (2011) 873.

46 D. Nakauchi, G. Okada, M. Koshimizu, and T. Yanagida: Radiat. Meas. 106 (2017) 170.

47 N. V. Skorodumova, S. I. Simak, B. I. Lundqvist, I. A. Abrikosov, and B. Johansson: Phys. Rev. Lett. 89 (2002) 166601.

48 C. Zhang, A. Michaelides, D. A. King, and S. J. Jenkins: Phys. Rev. B 79 (2009) 075433. 